
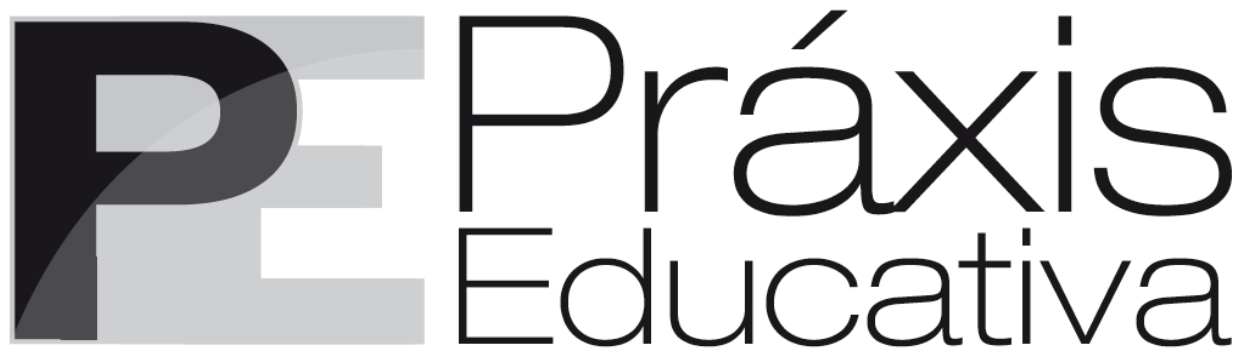

ISSN 1809-4031

elSSN 1809-4309

https://doi.org/10.5212/PraxEduc.v.15.15528.057

\title{
A Pedagogia como lócus de formação profissional de educadores(as): desafios epistemológicos e curriculares
}

\section{Pedagogy as a lócus of professional training of educators: epistemological and curricular challenges}

\section{La Pedagogía como locus de formación profesional de educadores(as): desafíos epistemológicos y curriculares}

(D) https:// orcid.org/0000-0003-0785-890X
Umberto de Andrade Pinto**
(iD) https://orcid.org/0000-0003-2691-8015
José Leonardo Rolim de Lima Severo
(iD) https:// orcid.org/0000-0001-5071-128X

Resumo: Este artigo consiste em um ensaio teórico que aborda, como questão central, as configurações formativas do curso de Pedagogia no Brasil. As reflexões propostas aportam-se em considerações sobre o estatuto epistemológico da Pedagogia e o seu lugar como Ciência da Educação no desenvolvimento da práxis profissional de educadores(as) em diferentes contextos. $\mathrm{O}$ artigo desenvolve críticas a perspectivas que deslocam o seu sentido como saber científico engajado na produção de sentidos e práticas que fortaleçam a dimensão humanizadora e o caráter público da educação. Em decorrência dessa orientação

\footnotetext{
* Pedagoga. Doutora em Educação (Filosofia da Educação). Professora titular Sênior da Faculdade de Educação Universidade de São Paulo (USP), onde coordena (em parceria) o Grupo de Estudos e Pesquisas sobre Formação do Educador (GEPEFE). Professora Associada no Programa de Pós-Graduação em Educação (Stricto sensu) da Universidade Católica de Santos. Membro do GT 4 - Didática da ANPEd. Pesquisador 1A CNPq. E-mail: <sgpiment@usp.br>.

** Pedagogo. Doutor em Educação. Professor Associado da Universidade Federal de São Paulo (UNIFESP), onde atua no Curso de Pedagogia, no Programa de Pós-Graduação em Educação, e no Programa de Pós-Graduação em Educação e Saúde na Infância e na Adolescência. Participa de dois grupos de pesquisas: GEPEPINFOR/UNIFESP e GEPEFE/FEUSP. Membro do GT 4 - Didática da ANPEd. E-mail: <uapinto@gmail.com>.

*** Pedagogo. Doutor em Educação. Professor Adjunto da Universidade Federal da Paraíba (UFPB), onde atua no Programa de Pós-Graduação em Educação. Líder do Grupo de Estudos e Pesquisas em Pedagogia, Trabalho Educativo e Sociedade (GEPPTES). Membro do GT 4 - Didática da ANPEd. E-mail: $<$ leonardorolimsevero@gmail.com>.
} 
A pedagogia como lócus de formação profissional de educadores(as): desafios epistemológicos e curriculares

crítica, traça-se uma perspectiva de organização curricular do curso baseada em eixos que buscam traduzir a complexidade da Pedagogia no intuito de demarcar sua especificidade e o seu compromisso com a formação de pedagogos(as) referenciada na concepção de educação como emancipação humana.

Palavras-chave: Ciência da Educação. Pedagogo. Projeto pedagógico.

Abstract: This paper consists of a theoretical essay that approaches, as a central question, the formative configurations of the Pedagogy degree's course in Brazil. The proposed reflections are based on considerations about the epistemological status of Pedagogy and its place as Science of Education in the development of the professional praxis of educators in different contexts. The paper develops critics about perspectives that changes its meaning as scientific knowledge engaged in the production of senses and practices that strengthen the humanizing dimension and the public character of education. As a result of this critical orientation, it traces a perspective of the curricular organization of the course based on axes that seek to translate the complexity of Pedagogy in order to demarcate its specificity and its commitment with the training of educators referenced in the conception of education as human emancipation.

Keywords: Science of Education. Pedagogue. Pedagogical Project.

Resumen: Este artículo consiste en un ensayo teórico que aborda, como cuestión central, las configuraciones formativas de la carrera de Pedagogía en Brasil. Las reflexiones planteadas se basan en consideraciones sobre el estatuto epistemológico de la Pedagogía y su lugar como Ciencia de la Educación en el desarrollo de la praxis profesional de educadores(as) en diferentes contextos. El artículo desarrolla críticas a perspectivas que cambian su sentido como saber científico dedicado a la producción de sentidos y prácticas que fortalezcan la dimensión humanizadora y el carácter público de la educación. Como consecuencia de esta orientación crítica, se traza una perspectiva de organización curricular de la carrera basada en ejes que buscan traducir la complejidad de la Pedagogía con la intención de demarcar su especificidad y su compromiso con la formación de pedagogos(as) referenciada en la concepción de educación como emancipación humana.

Palabras clave: Ciencia de la Educación. Pedagogo. Proyecto Pedagógico.

\section{Considerações introdutórias}

Há uma multidão de pessoas bem-intencionadas para pensar a Pedagogia (fora de si mesma), mas muito poucas para aceitar que o pedagogo pensa e se pensa. Ora, o pedagogo é um intelectual, desenvolve ideias em relação aos seus próprios atos, produz finalidade ligada aos atos. De certa maneira, o pedagogo recusa o especialista, reconbece o profissional e pratica o intelectual. Jean Houssaye (2004, p. 9).

As discussões sobre o Curso de Pedagogia como lócus de formação profissional revelam um apanhado de questões que foram emergindo e, ao mesmo tempo, ajudaram a configurar grande parte da agenda das políticas de formação docente no país. Problematizar as configurações formativas do curso partindo dos pontos de vista epistemológico e curricular implica reconhecer que o modo pelo qual a formação de pedagogos(as) se apresenta hoje, no que concerne às suas limitações e possibilidades, é o resultado de uma rede complexa de significados sobre as demandas atribuídas a esse curso e sobre sua identidade institucional como respostas a desafios históricos do contexto educacional brasileiro. Nesse contexto, tais respostas consolidaram, nas duas últimas décadas, o curso como uma licenciatura para a formação de professores(as) das etapas iniciais da Educação Básica, diferentemente de outros países.

Em contextos internacionais, o curso de Pedagogia desenha-se em torno da formação de pesquisadores(as), gestores(as) e diversas tipificações de perfis profissionais que se inserem no campo amplo da educação, estando a formação docente atribuída a outros cursos. Na Europa e também na América Latina, nos países nos quais se faz presente, o curso segue uma tendência curricular que, em comparação ao modelo de cursos superiores brasileiros, o configuraria mais

Práxis Educativa, Ponta Grossa, v. 15, e2015528, p. 1-20, 2020

Disponível em: <https://www.revistas2.uepg.br/index.php/praxiseducativa> 
como um bacharelado. O debate sobre a natureza formativa do curso de Pedagogia como licenciatura ou bacharelado, inclusive, tem sido deflagrado como alternativa para atender às necessidades de formação de pedagogos(as) para campos laborais que se atrelam a exigências formativas distintas daquelas para o magistério (PINTO, 2018).

Tendo como principal finalidade a formação inicial de professores(as) para a Educação Infantil e os anos iniciais do Ensino Fundamental, em acordo com as atuais Diretrizes Curriculares Nacionais (BRASIL, 2006), a Licenciatura em Pedagogia é objeto de críticas acerca da ausência de especificidades curriculares no tratamento da educação como fenômeno muito mais amplo do que a docência nesses níveis iniciais de escolarização. Essas críticas denunciam o apagamento de temas que, embora articulados ao eixo da formação docente, se vinculam a um espectro mais amplo de processos que transcendem o agir docente em sala de aula, tanto na escola quanto em outros espaços educativos não escolares. Contemplar tais processos na formulação e no desenvolvimento curricular da formação inicial de pedagogos(as) exige uma ruptura de compreensão do que constitui a Pedagogia como campo de conhecimentos, deslocando-a do sentido de tecnologia da ação docente para o sentido de Ciência da Educação.

No horizonte traçado por essas questões introdutórias, o objetivo deste texto é, partindo de uma abordagem sociopolítica e epistemológica, situar a especificidade do curso de Pedagogia como lócus efetivo de formação profissional de educadores(as), sinalizando eixos de organização curricular que, no quadro conceitual que mobilizamos, respondem ao desafio de correlacionar mais intrinsicamente a Pedagogia como campo de conhecimento e a Pedagogia como curso, tendo em vista o sentido humanizatório e emancipador das práticas sociais de educação. O argumento central defende a necessidade de que o curso de Pedagogia se consubstancie a uma teoria da Pedagogia cientificamente referenciada e socialmente engajada para formar educadores(as) que deverão atuar em diferentes espaços.

Nesse sentido, cabe destacarmos que, embora a centralidade da abordagem gire em torno do curso de Pedagogia, é possível que as análises aqui empreendidas, tanto acerca do entendimento do campo do conhecimento pedagógico, quanto dos aspectos propostos em relação à estruturação desse curso, possam também contribuir com outros cursos que formam professores (Licenciaturas) ou mesmo profissionais que atuam em áreas de confluência com a educação.

\section{A Pedagogia e o humano: um saber engajado e instituinte da humanização}

A educação é uma atividade exclusiva do humano e ocorre entre os seres humanos, com dupla e simultânea finalidade de, ao mesmo tempo que insere os novos humanos na sociedade existente, os constrói em sua subjetividade e os coloca também em contato com o outro, os outros, possibilitando-os verem-se entre os outros, na relação entre o que é igual e diverso. No dizer de Paulo Freire (1997, p. 1), “[...] não se pode encarar a educação a não ser como um que fazer humano [...] que ocorre no tempo e no espaço, entre os homens uns com os outros”. Em nossa perspectiva, o sujeito a ser educado é o sujeito com capacidade de transformar a realidade em que vive e, para sê-lo, necessita conhecer criticamente as condições concretas de sua realidade, se apropriar dos instrumentos que lhe permitam compreender como foram produzidas as situações de deshumanização presentes na atualidade. A educação praticada em diferentes espaços sociais necessita ser analisada em suas manifestações aparentes e implícitas, para que se explicite a gênese dessa deshumanização e como pode ser superada.

A Pedagogia é a ciência que tem esse papel: estudar a práxis educativa com vistas a equipar os sujeitos, profissionais da educação, dentre os quais o(a) professor(a), para promover as condições de uma educação humanizadora. Seu objeto de estudo é a educação nas várias 
A pedagogia como lócus de formação profissional de educadores(as): desafios epistemológicos e curriculares

modalidades em que se manifesta na prática social. Ao debruçar-se sobre o fenômeno educativo para compreendê-lo, amplia seu olhar, sua busca em outras ciências que também se debruçam sobre a complexidade do humano, síntese de múltiplas determinações. À Pedagogia compete investigar a natureza do fenômeno educativo, os conteúdos e os métodos da educação, bem como seus procedimentos investigativos, com vistas a articular essa complexidade em busca do humano humanizado e humanizador.

Quando incorpora a possibilidade de vincular-se ideologicamente à realidade educacional construindo-se como um saber engajado, em uma abordagem crítico-emancipatória, realça-se a práxis educativa como objeto da Pedagogia, em um movimento que integra intencionalidade e prática pedagógica; formação e emancipação do sujeito da práxis. Assim considerada, permite vislumbrar a construção de passarelas articuladoras entre as teorias educacionais e as práticas pedagógicas. Nessa perspectiva, revela-se como uma ação social de transformação e de orientação da práxis educativa da sociedade, desvelando as finalidades político/sociais presentes no interior da práxis e reorienta ações emancipatórias para sua transformação (FRANCO; LIBÂNEO; PIMENTA, 2007).

Nesse sentido, a educação caracteriza-se como processo de formação das qualidades humanas, e a Pedagogia é a ciência que estuda esse processo. Constituída teoricamente em torno do fenômeno educacional, estuda-o como processo em seus movimentos concretos, em sua historicidade, em suas contradições, na ação dos sujeitos, nos contextos onde ocorrem. E, ao fazêlo, cientificamente se transforma como teoria engajada, enquanto oferece perspectivas para transformação do real. Assim, a Pedagogia como ciência orienta a práxis, na medida em que os conhecimentos (teóricos) produzidos nessa dialética são propositivos, se articulam aos modos de agir, ao mesmo tempo ressignificando-os e sendo por eles ressignificada. A finalidade da Pedagogia é oferecer aos(às) educadores(as) perspectivas de análise para compreenderem a formação humana em contextos históricos, sociais, culturais, institucionais (inclusive de si mesmos) como profissionais, nas escolas ou em quaisquer outras modalidades ou espaços educativos nos quais se insiram para neles intervir, transformando-os. Daí decorre ser fundamental o permanente exercício da crítica das condições materiais nas quais o exercício profissional ocorre e de como, nessas condições, é produzida a negação da aprendizagem emancipadora.

$\mathrm{Na}$ história da humanidade, percebemos que as sociedades de algum modo sempre desenvolveram práticas e formas para inserir as crianças e os jovens na cultura existente, em formas de sobrevivência física, de pensar o mundo e suas relações com a natureza, com o outro, suas origens, seus valores, a criar e a transformar a vida. Na gênese dessas formas, encontramos a escola como instituição social, que, a partir de finais do século XVIII, vem se configurando nos moldes como a conhecemos na contemporaneidade por meio dos sistemas públicos de ensino. Desde então, a escola tem uma finalidade específica que é a de assegurar a formação educativa escolar de todas as crianças, todos os jovens e adultos nas comunidades, regiões, de diferentes países. No Brasil contemporâneo, sua trajetória mostra conquistas, como a ampliação do atendimento a quase todas as crianças e todos os jovens em idade escolar, ao mesmo tempo que evidencia enormes problemas, como a sonegação desse direito público, especialmente para os pobres. Por isso, o estudo dessa instituição se coloca como um dos principais fenômenos educativos a ser constituído no âmbito da ciência pedagógica, cujo sentido investigativo possibilita compreender suas raízes e seus determinantes, as causas histórico-político sociais da sonegação ao direito de humanização no qual ela, a escola, desempenha papel central.

\section{Identidade e pluralidade da Pedagogia}

O debate em torno da Pedagogia como ciência continua em aberto e atual em diversos países, protagonizado por estudiosos(as) da área educacional. No Brasil, ele assume um papel

Práxis Educativa, Ponta Grossa, v. 15, e2015528, p. 1-20, 2020

Disponível em: <https://www.revistas2.uepg.br/index.php/praxiseducativa> 
imperativo à medida que temos o curso de Pedagogia com uma tradição que já ultrapassa 80 anos, mas que atualmente descaracteriza a formação do(a) pedagogo(a) como profissional da educação quando prioriza e se reduz à formação do(a) professor(a) dos anos iniciais da Educação Básica. Uma vez que este estudo propõe contribuir com a proposta de alguns elementos estruturantes para a construção dos projetos pedagógicos (de cursos) que superem esse seu reducionismo a uma Licenciatura - de modo que problematize a Pedagogia como campo de conhecimento e, ao mesmo tempo, garanta a formação profissional efetiva do(a) pedagogo(a) - discutiremos, a seguir, a especificidade da Pedagogia como ciência e, posteriormente, suas implicações na formação desse(a) profissional.

O objeto de estudo da Pedagogia é a educação, fenômeno estritamente humano e multideterminado, como visto anteriormente. Isso lhe confere uma complexidade que a difere das outras ciências humanas, que, ao se debruçarem sobre a condição humana, nem sempre estão envolvidas diretamente com uma atividade também prática. De modo diferente, a educação, que embora seja estudada como evento que já ocorreu (daí a tradição dos estudos na área da história da Pedagogia/educação), trata-se de um fenômeno pesquisado predominantemente enquanto se manifesta em diferentes contextos por quem o examina e, também, pelos agentes que dele próprio participa. Além dessa dimensão da pesquisa em seu sentido stricto sensu, a Pedagogia manifesta-se como ciência na atuação profissional $\operatorname{dos}($ as) educadores(as) que mobilizam e articulam um conjunto de saberes de diferentes matrizes que orientam a prática pedagógica em situações específicas, nem todos diretamente procedentes do conhecimento científico. Essa peculiaridade dos fenômenos educativos é que faz da Pedagogia uma ciência de elevado grau de complexidade.

Esse complexo campo de conhecimentos da Pedagogia, em especial na contemporaneidade, é ainda fortemente marcado pelos avanços da intensa produção científica e tecnológica, de modo que a educação, como objeto de estudo, é compartilhada por diferentes ciências que, com diferentes inserções, contribuem efetivamente para o seu caráter científico. Estamos aqui nos referindo às denominadas "ciências da educação".

Por um lado, do mesmo modo que a Pedagogia, as ciências da educação também têm sido objeto de debate em alguns países europeus no que se refere à sua constituição epistemológica. Em Portugal, país com o qual temos tido um intenso intercâmbio acadêmico nas últimas décadas, além de serem oferecidas como um curso de Graduação, vários(as) dos(as) seus(as) pesquisadores(as) têm problematizado sua problemática epistemológica (AFONSO, 2013; BOA VIDA; AMADO, 2008; CARVALHO, 1996). Por outro lado - e contraditoriamente -, se a Pedagogia é questionada no que se refere à sua cientificidade, o questionamento em torno das ciências da educação referese à sua legitimidade identitária como um campo científico unitário no tratamento prático das questões educacionais. De fato, se a Pedagogia historicamente foi entendida mais como uma arte do que como uma ciência por envolver uma atividade prática, as ciências da educação, ao se constituírem como tal para tratar cientificamente das questões educacionais, tendem mais a um tratamento analítico das questões educacionais, do que, na verdade, responderem diretamente a uma intervenção na prática pedagógica.

Assim, um dos grandes desafios das ciências da educação é tratar do fenômeno educativo sob os diferentes aportes de cada uma dessas ciências, dialogando organicamente com os demais saberes mobilizados no tratamento prático desse fenômeno. Frequentemente, o que ocorre é cada uma dessas ciências se aproximar do fenômeno educativo separadamente, a partir do seu referencial teórico e metodológico, de modo que a problemática em torno do referido fenômeno fica sempre parcialmente abordada (PIMENTA, 2010). Desse modo, em vez da abordagem de cada um dos problemas educacionais ser objeto de análise a partir das contribuições da Sociologia da Educação, da Psicologia da Educação, da História da Educação etc., comumente ele é tratado por uma dessas 
ciências que o analisa circunscrito, exclusivamente, no âmbito de sua ciência-mãe. Nesse sentido, compartilhamos do argumento de Wachowicz (2009) de que o conhecimento para ser libertador necessita voltar-se ao problema que motivou a sua produção.

\begin{abstract}
Tratamos de um processo muito complexo, o qual dividimos em partes para melhor compreendê-lo, sem esquecer jamais que as partes pertencem a um todo. E nesse conjunto o que mais importa compreender é a relação que se estabelece entre as partes, não as mesmas em si. Já sabemos que um todo não é a soma das partes, mas apresentase diferente a cada momento em que as relações mudam entre as partes. (WACHOWICZ, 2009, p. 9).
\end{abstract}

Essa visão de totalidade no que se refere à abordagem dos problemas educacionais está presente no conceito de Pedagogia como ciência prática, desenvolvido por Schmied-Kowarzik (1988), e se alinha com a defesa da educação articulada à emancipação da condição humana.

Cabe destacarmos, já de início, que, ao apregoarmos a Pedagogia como ciência prática, é em uma perspectiva radicalmente oposta aos princípios que fundamentam as políticas públicas hegemônicas na área de formação de educadores(as) no Brasil, que proclamam um praticismo nos limites da racionalidade técnica, como se a prática pedagógica pudesse ser prescrita. De modo oposto, a implementação de uma Pedagogia emancipadora deve se articular a uma abordagem dialética das relações entre educação e sociedade. Nesse sentido, Severino (2001) afirma que não podem ser desconsiderados alguns elementos fundamentais na apreensão, na descrição e na interpretação dos fenômenos educacionais submetidos a uma abordagem epistêmica dialética. Dentre outros elementos, ele destaca que

[...] um conhecimento sobre a educação que se pretenda rigoroso e científico não pode deixar de levar em consideração as forças de opressão e de dominação que atuam na rede das relações sociais, que faz da sociedade humana uma sociedade política, hierarquizada e atravessada pelo poder da dominação. Todo conhecimento que tem a ver com a educação não pode deixar de enfrentar, de modo temático explícito, a questão do poder, elemento que marca incisivamente toda expressão concreta da existência humana. (SEVERINO, 2001, p. 19).

Severino (2001) diferencia o campo de conhecimento das Ciências Humanas (Psicologia, Antropologia etc.) do campo da Ciência da Educação justamente na praxidade de seu objeto. Segundo o autor, "[...] quando entramos no campo da ciência da educação, impõe-se agregar um outro elemento do olhar científico, que possa dar conta [...] do caráter eminentemente práxico da educação" (SEVERINO, 2001, p. 17).

E por que caráter práxico e não caráter prático da educação? Ao empregarmos a expressão práxico, identificamos a potência da educação como uma atividade prática carregada de uma intenção (teoria) transformadora da realidade. Essa expressão advém do conceito de práxis desenvolvido por Marx e Engels. Em duas das suas teses sobre Feuerbach, eles afirmam que:

A questão de saber se cabe ao pensamento humano uma verdade objetiva não é uma questão teórica, mas prática. É na práxis que o homem deve demonstrar a verdade, isto é, a realidade e o poder, o caráter terreno de seu pensamento [...]. A doutrina materialista sobre a alteração das circunstâncias e da educação esquece que as circunstâncias são alteradas pelos homens e que o próprio educador deve ser educado [...]. A coincidência da modificação das circunstâncias com a atividade humana ou alteração de si próprio só pode ser apreendida e compreendida racionalmente como práxis revolucionária. (MARX; ENGELS, 1979, p. 12).

Assim, o conceito de práxis está intimamente vinculado à prática, uma vez que esta é a referência para a transformação da realidade - não uma prática qualquer, mas, sim, uma prática carregada de intencionalidade, como expressão do caráter terreno do pensamento. 
Para Marx (VÁZQUEZ,1968), não basta conhecer e interpretar o mundo de diferentes maneiras, o que importa é transformá-lo. Em "Filosofia da Práxis", Vázquez (1968) afirma que "[...] a relação teoria e práxis é para Marx teórica e prática; prática, na medida em que a teoria, como guia da ação, molda a atividade do homem, particularmente a atividade revolucionária; teórica, na medida em que essa relação é consciente" (VÁZQUEZ,1968, p. 117).

Vázquez (1968, p. 185) diferencia práxis de atividade, argumentando que "[...] toda práxis é atividade, mas nem toda atividade é práxis". Reside aí o caráter práxico da educação identificado por Severino (2001). Desse modo, a educação, como atividade humana intencional, não é uma atividade qualquer, mas, sim, uma atividade prática saturada de teoria. Diferentemente de outras atividades humanas orientadas por uma referência teórica de senso comum, e aí podemos falar de práticas educativas informais (não-intencionais), a educação (intencional) tem uma referência teórica de cunho investigativo-filosófico (ciência-ética).

Nessa mesma perspectiva, Saviani (2011) contribui com a distinção entre a Pedagogia e as Ciências da Educação ao tratar dos conceitos de ideias educacionais e ideias pedagógicas. Ele emprega a expressão "ideias educacionais" para referir-se àquelas ideias que se reportam à educação a partir da análise do fenômeno educativo, trabalho este desenvolvido tanto pelas Ciências da Educação quanto pela Filosofia da Educação. Por outro lado, as ideias pedagógicas incorporam “[...] as ideias educacionais, não em si mesmas, mas na forma como se encarnam no movimento real de educação, orientando e, mais do que isso, constituindo a própria substância da prática educativa" (SAVIANI, 2011, p. 6). Assim, podemos igualar esse conceito de ideias pedagógicas ao de teorias pedagógicas, mas não ao de teorias educacionais. Essas últimas são teorias sobre a educação, e não são necessariamente teorias pedagógicas. Assim, Saviani (2008) reserva o termo "pedagógica" à ideia da prática educativa, tanto que acaba por concluir que "[...] se toda Pedagogia é teoria da educação, nem toda teoria da educação é Pedagogia [...] o conceito de Pedagogia se reporta a uma teoria que se estrutura a partir e em função da prática educativa" (SAVIANI, 2008, p. 258).

Nessa mesma abordagem epistemológica, Pinto (2011) busca ampliar o entendimento da Pedagogia como ciência prática a partir das contribuições de Libâneo (2010), Pimenta (1996) e Franco (2008). O autor identifica a Pedagogia como campo de conhecimento sobre e na educação. Campo de conhecimento, pois não se trata apenas de teorias científicas, na medida em que a prática educativa envolve outras formas e tipos de conhecimento (senso comum, estética, ética/política, empiria, religioso etc.). Assim, a Pedagogia constitui-se por uma abordagem pluricognitiva ao ser expressão desses diferentes tipos e formas de conhecimento. Entretanto, ao mesmo tempo, a Pedagogia constitui-se por uma abordagem transdisciplinar dos fenômenos educativos ao articular e sintetizar a produção científica das diferentes Ciências da Educação, tanto das clássicas (Psicologia, Sociologia, História e Filosofia), quanto daquelas que ainda estão construindo um espaço acadêmico junto à área de educação (Biologia, Antropologia, as Neurociências etc.), mas muito têm contribuído com o avanço nos estudos educacionais nos últimos tempos. Por outro lado, a Pedagogia constitui-se como campo de conhecimento na educação ao materializar-se nas práticas educativas que estão em movimento, que estão acontecendo; e sobre a educação, por teorizar, sistematizar, rever e ampliar as práticas educativas já experimentadas historicamente.

Assim, podemos associar o conceito de teoria pedagógica, conforme Saviani (2008), com o conhecimento pedagógico produzido sobre e na educação. Dessa forma, por teorias pedagógicas, identificamos o conhecimento produzido historicamente na área de educação a partir da sistematização de práticas educativas já vivenciadas, assim como aquele conjunto de saberes mobilizados no âmago da ação educativa ainda em movimento.

Nessa mesma direção, Franco, Libâneo e Pimenta (2011) identificam a práxis educativa como objeto de estudo da Pedagogia, advogando o entendimento de práxis como transformação e criação, 
A pedagogia como lócus de formação profissional de educadores(as): desafios epistemológicos e curriculares

na medida em que atribui um novo sentido à condição humana articulado a uma concepção de mundo. Daí sintetizarem uma nova dimensão conceitual à Pedagogia. Para os autores:

A práxis educativa, objeto da ciência pedagógica, caracteriza-se, assim, pela ação
intencional e reflexiva de sua prática. Ela é distinta de outras práticas sociais, que até
podem funcionar, em certos momentos, como práticas educativas, mas que prescindem
dessas condições e que, por não serem organizadas intencionalmente, não serão objeto
de estudo da Pedagogia, apesar de estarem incluídas no contexto amplo da Educação. A
práxis educativa ocorre prioritariamente em locus formais, especialmente na escola, mas
não exclusivamente, pois ocorre na família, pode acontecer no trabalho, nos processos
de comunicação social, entre muitos, onde houver uma intencionalidade a se concretizar,
permeada por um processo reflexivo de fins e meios. (FRANCO; LIBÂNEO;
PIMENTA, 2011, p. 65).

Neste texto, defendemos que essa intencionalidade das práticas educativas deve estar também presente nos projetos pedagógicos dos cursos de formação dos diferentes profissionais de nível superior, em especial, nos cursos de Pedagogia. Nesses cursos, mais ainda do que ter clareza da intenção na formação do(a) pedagogo(a), urge discutir exatamente esse sentido epistemológico da própria Pedagogia como ciência.

A partir dessa compreensão da Pedagogia como ciência prática, cabe então questionarmos: que tipo de abordagem deve ter um currículo do curso de Pedagogia? Em uma sentença, poderíamos dizer que sua centralidade deve ocorrer em torno das práticas pedagógicas em diferentes cenários de atuação profissional do(a) pedagogo(a).

Tradicionalmente, o currículo dos cursos de Pedagogia é dividido entre as disciplinas teóricas e as disciplinas práticas, com certa tendência dessas últimas serem oferecidas mais ao final do curso; assim como os espaços de atuação profissional entrarem em cena somente no momento do Estágio Supervisionado. Essas dicotomias reproduzem a mesma situação existente em outros cursos de nível superior, que comumente acabam por ser identificados - em especial nas instituições de Ensino Superior públicas - como cursos muito teóricos. Em relação à essa crítica, o que devemos questionar é que tipo de teoria é desenvolvida nesses cursos. O que se espera da teoria é que ela dialogue com a realidade do campo de atuação profissional. No caso dos cursos de Pedagogia que se propõem formar educadores(as) para trabalharem na educação pública em diferentes espaços, o que se espera das teorias que serão desenvolvidas em seu currículo é que contribuam para que seus alunos consigam compreender a realidade das instituições educacionais públicas do país, desde os aspectos mais amplos - como a organização histórica e pedagógica do sistema educacional brasileiro - até os aspectos mais específicos, como a constituição social e cultural de determinada comunidade próxima de onde a instituição formadora está inserida. Assim sendo, as aulas de História de Educação, de Sociologia da Educação, e mesmo de Filosofia da Educação devem contribuir com a leitura dessa realidade, o que se efetiva com a pesquisa do real (PIMENTA; LIMA, 2017).

Nessa direção, a dicotomia teoria $\times$ prática desfaz-se. As Ciências da Educação - que na tradição dos cursos de Licenciatura no Brasil são identificadas como disciplinas de Fundamentos da Educação - passam a desenvolver teorias que dialogam com a realidade educacional brasileira, quando mobilizadas pelos(as) pedagogos(as) para compreenderem os fenômenos e transformá-los, ou seja, em sua práxis. Com isso, não queremos deixar de reconhecer que determinadas disciplinas tendem a ter uma abordagem mais teórica do que outras, o que não seria um problema, desde que elas não se percam em estudos teóricos que se desconectem da realidade. Em um curso de Pedagogia, isso não pode acontecer. Em uma Graduação de Filosofia, por exemplo, é de se esperar que muito das teorias estudadas não estabeleçam relação imediata com a realidade, mas em um curso de Pedagogia, cujo objeto de estudo é a Educação, isso não pode ocorrer. Toda a teoria aí

Práxis Educativa, Ponta Grossa, v. 15, e2015528, p. 1-20, 2020

Disponível em: <https://www.revistas2.uepg.br/index.php/praxiseducativa> 
desenvolvida deve dialogar diretamente, ou mesmo indiretamente, com a realidade educacional. Daí a defesa da Pedagogia como ciência prática. Assim, na organização curricular do curso, as teorias educacionais devem ser desenvolvidas em constante diálogo e referência às teorias pedagógicas, lembrando, como visto anteriormente, que as teorias educacionais não devem ser estudadas isoladas em si mesmas, mas, sim, no modo como se materializam nas práticas (teorias) pedagógicas.

É importante destacarmos, nesse sentido, que as Ciências da Educação não se opõem à Pedagogia. Elas não devem ser contrapostas, mas, sim, entendidas em uma perspectiva de complementaridade, uma vez que as primeiras auxiliam na constituição científica da segunda.

Diferentemente da ideia prescritiva de um roteiro pré-estabelecido para a ação do(a) educador(a), o que se propõe é que as atividades curriculares do curso de Pedagogia direcionem $o$ (a) futuro(a) pedagogo(a) a observar um contexto de atuação profissional, de modo que compreenda os elementos que explicam a especificidade dessa determinada situação educacional, de modo a ampliar a leitura dessa situação por meio de um intenso exercício analítico propiciado pelas teorias educacionais e pedagógicas. Entretanto, para analisar uma determinada situação educacional, os alunos do curso devem ter um repertório teórico que, de forma espiral, vá crescendo ao longo das aulas, ao longo do curso. Daí o papel nuclear no interior do curso que o Estágio Supervisionado deve assumir, rompendo com a tradição de uma unidade curricular isolada das demais unidades curriculares do curso e sob a responsabilidade de um único professor formador. Assim, o Estágio Supervisionado deve ocupar um lugar central e articulador no projeto pedagógico do curso (PIMENTA; LIMA, 2017), de modo que todo o corpo docente se envolva com ele, seja em relação aos temas e/ou disciplinas mais voltadas às teorias educacionais, ou em relação aos temas e/ou disciplinas mais voltadas às teorias pedagógicas.

No intuito de traduzir a argumentação epistemológica e as proposituras formativas desenvolvidas ao longo deste texto em possibilidades orientadoras da organização e do desenvolvimento do currículo do curso de Pedagogia, a seguir serão apresentados eixos curriculares estruturantes que, como síntese das possibilidades traçadas neste texto, apontam para uma formação de pedagogos(as) consubstanciada em uma concepção de Pedagogia como ciência.

\section{Eixos estruturantes para um curso de Pedagogia}

Os elementos teóricos mobilizados no debate sobre o reconhecimento da natureza científica da Pedagogia, manifestada na práxis que (re)cria saberes e práticas de formação humana em diferentes contextos sociais, permitem derivar questões sobre finalidades e formas de organização curricular para o curso de Pedagogia na tentativa de alinhá-lo a eixos estruturantes que traduzam a complexidade do campo pedagógico. Essa complexidade refere-se, antes de tudo, ao caráter multirreferencial da base de conhecimentos que organiza o curso de Pedagogia e à pluralidade de cenários e estratégias de trabalho pedagógico em espaços escolares e não escolares. Isso faz com que o curso incorpore atribuições que se espraiam na formação de um(a) profissional com amplo espectro de possibilidades de atuação. O modo pelo qual tal complexidade é compreendida incide em formas diversas de representar os objetos formativos do curso de Pedagogia e os delineamentos metodológicos que caracterizam um currículo de formação inicial de pedagogos(as). Pressupõe-se, portanto, que propostas de organização curricular para o curso de Pedagogia não podem prescindir de uma estruturação teórico-metodológica inscrita no quadro de elementos conceituais do debate sobre a própria Pedagogia como campo de conhecimento. É, portanto, imprescindível que todos os cursos de Pedagogia contemplem a Pedagogia. 
A pedagogia como lócus de formação profissional de educadores(as): desafios epistemológicos e curriculares

No que se refere a esse paradoxo em relação aos cursos de Pedagogia no Brasil não discutirem a própria Pedagogia, vale o alerta do professor Celestino Alves Silva Junior quando afirma que

\begin{abstract}
Como todos sabemos, o curso de Pedagogia não costuma olhar para si mesmo, o que explica o fato de ainda não ter percebido que a Pedagogia como disciplina acadêmica nunca teve espaço reservado em seu interior. Essa situação surreal poderá se tornar a antecedente de outra situação ainda mais surreal: se um dia a organização curricular por disciplinas for abandonada, a disciplina Pedagogia não será afetada, não porque terá sido preservada, mas porque jamais foi considerada. (SILVA JUNIOR, 2019, p. 6).
\end{abstract}

Assim, o que defendemos é que o curso de Pedagogia estude ela mesma como uma disciplina, um saber disciplinar estruturante e integrador de todo o projeto pedagógico dos cursos, contemplando o seu desenvolvimento histórico como ciência e suas diferentes perspectivas conceituais, em uma dimensão intrínseca dos processos formativos do(a) futuro(a) pedagogo(a).

No Brasil, produções acadêmicas dedicadas ao debate epistemológico da Pedagogia e suas implicações na configuração da formação de pedagogos(as) (PIMENTA, 1996; FRANCO; 2008; FRANCO; LIBÂNEO; PIMENTA, 2007; LIBÂNEO, 2010; PIMENTA; 2010; PINTO, 2011) se revelam atravessadas pela busca permanente de elucidação do seu estatuto científico e dos riscos do seu apagamento acadêmico e social quando da recorrente tentativa de imprimir tendências neotecnicistas e eficientistas que a restringem, como campo e como curso, ao universo dos fazeres relativos à instrução. Essas tendências acentuam uma dimensão tecnológica da Pedagogia que, dissociada da reflexão sobre o sentido educativo e suas conexões com a dinâmica conjuntural da sociedade, enfraquece uma perspectiva crítica de compreensão sobre o perfil do(a) profissional egresso. Igualmente, fragmentam a relação entre teoria e prática pedagógica, de modo a inviabilizar a práxis humanizadora e emancipatória que funda o objeto da Pedagogia: a educação como prática de transformação da sociedade.

A fim de confrontar tais tendências, atualmente em destaque na agenda reformista da educação no Brasil, parece ser fundamental problematizar o "pedagógico" do curso de Pedagogia a fim de verter eixos estruturantes para a sua organização curricular; eixos que representam possibilidades de desenhar uma proposta formativa que busque assegurar conexões sólidas entre fundamentos e métodos do trabalho pedagógico, como também uma orientação ético-política fruto de um projeto de sociedade equânime, justa e democrática.

O "pedagógico" assume conotações diversas e tem sido empregado como um qualitativo de saberes, práticas, métodos, recursos etc. Em meio a uma profusão de usos e abusos, nota-se um certo esvaziamento de sentido que cerca a categoria "pedagógico" na sua relação com a própria natureza da Pedagogia, resumindo-a ao campo metodológico ou didático, principalmente. Libâneo (2010, p. 30) assinala que o "pedagógico" [...] refere-se a finalidades da ação educativa, implicando objetivos sociopolíticos a partir dos quais se estabelecem formas organizativas e metodológicas da ação educativa”.

Logo, o "pedagógico" exprime um sentido que engloba a multidimensionalidade dos processos de formação humana, irredutível a qualquer forma de dissociação entre teoria e prática ou de fragmentação entre as dimensões que organizam as práticas educativas que se processam desde a concepção à avaliação. É sob essa perspectiva que um curso de Pedagogia deveria se organizar, na medida em que se volta à formação de profissionais que elaborem e mobilizem referências teórico-metodológicas e estratégias educativas mediadas por uma racionalidade práxica que se nutre do conhecimento do âmbito educacional como forma de responder cientificamente aos desafios desse mesmo âmbito. Como discutido anteriormente, trata-se de um pensar implicado por intencionalidades que se expressam na tomada de consciência e na transformação da prática.

Práxis Educativa, Ponta Grossa, v. 15, e2015528, p. 1-20, 2020

Disponível em: < https://www.revistas2.uepg.br/index.php/praxiseducativa> 
Embora se produza na relação com discursos culturais que permeiam as proposições de um saber específico sobre educação, a Pedagogia, por meio da práxis de pedagogos(as), encontra na ciência seu lugar de elaboração (ZULUAGA GARCÉS, 1993), o que não significa ignorar as relações de saber que geram coesão entre o que se entende ou se valora como ciência e os interesses que movimentam a sociedade ao longo da história. A ciência é, em si mesma, produto de relações históricas e trata de dar forma e sentido a um corpo de saberes especializados cuja relevância é assinalada pelos usos sociais a que se destina. Quando se defende a natureza científica da Pedagogia, nota-se que "[...] lo que se critica es que se haya separado la pedagogía de las conceptualizaciones, que se le haya recortado su capacidad de reconceptualizar en su seno el concepto de educación [...]" (ZULUAGA GARCÉS, 1993, p. 122)

Nesse sentido, o pedagógico é a extensão do caráter científico da Pedagogia que imprime identidade aos saberes e às práticas exercidos sob a práxis de profissionais especializados(as) com sólida formação teórico-prática capazes de interpelar a realidade social e suas determinações na práxis da educação em seu cerne, e de propor possibilidades de melhora da qualidade dos processos educativos em suas diferentes formas de manifestação no marco de uma concepção críticoprogressista de sociedade. Não se trata, portanto, de um atributo cujo sentido se baseie em uma racionalidade exógena à Pedagogia como Ciência da Educação ou que seja fruto de apropriações bastante comuns que associam o pedagógico a um caráter não científico ou meramente prescritivo e/ou instrucional.

Reconhecer que as diferentes formas de encarar a especificidade do campo pedagógico se traduzem em arranjos distintos de saberes e experiências na formação de pedagogos(as) leva à compreensão de que uma concepção epistemológica da própria Pedagogia como Ciência se constitui em um elemento importante que funda e organiza currículos capazes de delinear e conectar diferentes componentes sob o critério de sua pertinência ao âmbito da educação e à potencialidade em relação às demandas e aos desafios atribuídos à profissão de pedagogo(a).

É interessante recorrer à distinção que Touriñan López (2018) faz entre âmbito de conhecimento e conhecimento do âmbito, sendo este o elemento estruturante dos cursos de formação profissional. Segundo o autor, um âmbito de conhecimento diz respeito a qualquer dimensão da realidade que seja cognoscível, investigável e ensinável. Assim, a educação é um âmbito cujos sentidos e configurações práticas são susceptíveis de produção de conhecimentos que se vinculam a racionalidades plurais, entre elas a pedagógica. Os referenciais derivados desse processo gnosiológico incidem na conformação de um corpo sistêmico de conhecimento do âmbito educacional, sendo este a Pedagogia. Argumentando que o conhecimento específico do âmbito da educação se configura pela e na Pedagogia mediante conexões que a implicam em diálogos inter e transdisciplinares, o autor esclarece que "[...] en la carrera de Pedagogía aprendemos a descobrir, inventar, innovar en educación como actividad, como ámbito de realidad y como ámbito de conocimiento, perfeccionando nuestro conocimiento del ámbito" (TOURIÑAN LÓPEZ, 2018, p. 117).

Nessa lógica, o curso de Pedagogia é o lugar privilegiado de formação especializada no conhecimento do âmbito educacional, conduzida por uma racionalidade crítica sensível às condições sociais, políticas e culturais dos contextos de formação humana, como lembra Saviani ao afirmar a necessidade de organizar "[...] o espaço específico para os estudos e pesquisas educacionais que, em nível de graduação, gira em torno do curso de Pedagogia" (SAVIANI, 2007, p. 134).

Pensar a Pedagogia como lócus de profissionalização supõe que não se confunda o campo pedagógico com estudos interdisciplinares em educação, notadamente assumidos por especialistas em campos que colaboram com a reflexão científica sobre os processos educativos, e que não se 
A pedagogia como lócus de formação profissional de educadores(as): desafios epistemológicos e curriculares

negue a contribuição da pesquisa aplicada em Ciências Humanas e Sociais como referência para os desenhos curriculares.

A partir desses princípios fundamentais que se conectam organicamente à argumentação desenvolvida nos tópicos anteriores, é possível visualizar alguns eixos que colaboram com o dimensionamento dos currículos dos cursos de Pedagogia na perspectiva da crítica às tendências que, atualmente e outrora, incidem na descaracterização do caráter práxico dessa formação, fundado na relação entre pesquisa e prática pedagógica transformadora do real. Tal caráter se vincula a uma concepção de educação como processo de interação humana multifacetado e complexo em função de múltiplas conexões entre contextos políticos, psicossociais, culturais e institucionais que se dinamizam nos tempos e nos espaços sociais.

Na contramão dessa compreensão, a Base Nacional Comum da Formação Docente (BRASIL, 2019) corporifica uma tendência desintelectualizante e neotecnicista distante de uma concepção de formação pedagógica comprometida com a melhoria da qualidade social da educação. As proposições contidas nesse documento alinham-se a uma lógica formativa que simplifica os saberes e as habilidades para o exercício profissional de pedagogos(as) ao domínio de competências para o ensino e sem referências à dimensão teórico/investigativa que configura o trabalho pedagógico desenvolvido na sala de aula e em outros espaços de atuação.

Por essa razão, é mais do que importante problematizar o que pode ser o curso de Pedagogia em uma sociedade de contradições e políticas que o enfraquecem como lócus de formação de educadores(as) cientificamente criativos(as) e socialmente engajados(as). Isso favorece a capacidade de reflexão investigativa sobre as suas práticas como dimensão constitutiva do seu desenvolvimento profissional, compreendendo-as nas relações entre sociedade, conhecimento e formação humana. Tomando as atividades profissionais como objetos de investigação e análise pedagógica, o(a) pedagogo(a) poderá construir, continuamente, saberes que integram o repertório da Pedagogia com construtos que se estruturam por meio da racionalidade práxica. Igualmente, poderá desenvolver ferramentas de intervenção inovadora diante dos desafios que atravessam seus contextos de inserção, favorecendo a autonomia profissional e uma cultura de trabalho críticoreflexivo.

Desse modo, a seguir, serão apresentados e analisados os eixos estruturantes com os quais esperamos contribuir na implementação de projetos pedagógicos para os cursos de Pedagogia na perspectiva desenvolvida ao longo deste texto. São eles: a) a pesquisa como forma de aprendizagem do pensamento científico e dimensão do desenvolvimento profissional; b) a relação articulada entre teoria e prática permanente no/pelo currículo; c) experiência formativa pela imersão nos contextos educativos; d) compromisso com a finalidade democrática dos processos educativos e com a escola pública; e) o estudo da Didática em suas conexões com as bases teórico-práticas da relação pedagógica e as especificidades dos objetos do ensino.

O primeiro eixo, a pesquisa como forma de aprendizagem do pensamento cientifico e dimensão do desenvolvimento profissional, implica uma forma de organização curricular propícia para a articulação entre teoria e prática pedagógica como processo de produção de saberes e aperfeiçoamento da capacidade analítica necessária à abordagem problematizadora das situações e dos contextos de trabalho, bem como à construção de alternativas de intervenção que respondam a desafios.

Uma investigação exploratória de projetos curriculares de cursos de Pedagogia no estado de São Paulo, desenvolvida por Pimenta et al. (2017), aponta que, no total de 7.203 disciplinas mapeadas no conjunto de 144 cursos de instituições públicas e privadas, apenas 7,47\% se vinculam a conhecimentos sobre ações de pesquisa e trabalho de conclusão de curso/monografia. Segundo os(as) autores(as), os dados indicam "[...] uma preocupação maior dos cursos com os 
conhecimentos relacionados à organização metodológica do trabalho científico do que com a formação do professor para a pesquisa" (PIMENTA et al., 2017, p. 22).

É importante salientarmos que dimensionar a pesquisa como eixo de organização curricular do curso de Pedagogia não depende exclusivamente da inserção de disciplinas de metodologia do trabalho científico ou mesmo de fundamentos investigativos e trabalho de conclusão de curso. Como discutem Pedroso e Pinto (2019), a partir de apontamentos de uma pesquisa com coordenadores(as) de cursos de Pedagogia do estado de São Paulo, os processos de pesquisa na formação de pedagogos(as) que buscam superar a fragmentação entre pensamento e ação, muitas vezes atualizada por arranjos curriculares que optam por componentes estanques, tendem a se caracterizar por uma articulação mais dinâmica e capilarizada nos currículos e, também, são contemplados por meio de metodologias que associam o ensinar e o aprender à reflexão investigativa.

Ao lançarem mão de metodologias do ensinar pela e com a pesquisa, professores(as) e estudantes " $[. .$.$] analisam o conhecimento historicamente construído, compreendem suas raízes,$ seus contextos de produção, posicionam-se criticamente diante deles e constroem outros conhecimentos" (PEDROSO; PINTO, 2019, p. 175). Como eixo estruturante, a pesquisa necessita ser contemplada tanto por componentes específicos e integrados vertical e horizontalmente no currículo, mas também por metodologias didáticas que estimulem, nos(as) estudantes, o desenvolvimento da autonomia intelectual, da postura crítico-reflexiva e da atitude criativa em face dos desafios que configuram os contextos educativos.

Sem a criação e o fortalecimento de uma cultura de aprendizagem baseada na atitude epistemológica de indagação, crítica, pensamento analítico e conceituação fortemente promovida pela inserção em contextos educativos concretos, o currículo do curso de Pedagogia contribuirá pouco para a elaboração crítico-reflexiva da experiência dos(as) estudantes, visando à unidade entre teoria e prática com a finalidade de conhecer, de elucidar e de transformar as múltiplas condições que permeiam o trabalho pedagógico. Essa elaboração crítico-reflexiva é entendida como práxis uma vez que se apoia na articulação orgânica entre "[...] as dimensões de conhecimento e de intencionalidade (atividade teórica) e a de intervenção e transformação (atividade prática) da atividade docente [...]” (PIMENTA, 1995, p. 61).

Situando a pesquisa como instrumento de ampliação da consciência sobre a experiência de práxis no curso de Pedagogia, é possível depreender um segundo eixo de organização curricular como sendo a relação articulada entre teoria e prática permanente no/pelo currículo. Tradicionalmente, desde a Lei de Diretrizes e Bases da Educação N 4.024, de 20 de dezembro de 1961 (BRASIL, 1961), o núcleo básico do curso de Pedagogia caracteriza-se pela organização baseada em disciplinas que se dimensionam em áreas de fundamentos da educação, organização do trabalho pedagógico, didática, metodologias de ensino e estágios. Ao longo do tempo, a nomenclatura dos respectivos componentes tem variado, mas, no esquema do corpo de conhecimentos convencionados como fundamentos da educaşão, que correspondem, grosso modo, ao que apresentamos anteriormente como Ciências da Educação, mantem-se a aplicação dos campos da Sociologia, da Antropologia, da Psicologia, da Filosofia, da História, da Economia, da Biologia etc. Conforme discutido anteriormente, a multidimensionalidade do enfoque pedagógico implica a Pedagogia em relações transdisciplinares com diferentes fontes epistemológicas. Entretanto, essa pluralidade de referências derivadas de estudos e de pesquisas sobre educação nem sempre é equacionada de forma articulada e orientada para um foco convergente no desenho e no desenvolvimento dos currículos ou mesmo na organização funcional das próprias faculdades ou centros de Educação, assim como nem sempre convergem ao estudo da práxis educativa que se realiza na sociedade humana. 
A pedagogia como lócus de formação profissional de educadores(as): desafios epistemológicos e curriculares

É possível estabelecermos algumas hipóteses que exploram o quadro crítico acerca do papel que desempenham os fundamentos da educação na construção de experiências formativas conducentes à atividade teórico-prática no curso de Pedagogia. Em pesquisa anterior (SEVERO, 2018), observou-se que, não raramente, são representados por disciplinas sobrepostas, no início do curso, com ementas que mais sinalizam uma síntese teórico-metodológica da área de referência sem contribuir, efetivamente, com a análise dos problemas pedagógicos. Seguramente, as contribuições dessas áreas incidem na ampliação e na sustentação científica do campo pedagógico, mas, segundo o enfoque adotado, podem materializar currículos com fortes fronteiras disciplinares, dada a ausência de clareza quanto ao critério de pertinência à formação de pedagogos(as) e enlaces com as dimensões teórico-práticas da educação.

Carr (2002) infere que a ausência da compreensão sobre os critérios epistemológicos da teoria da educação como uma síntese analítica de um programa interdisciplinar de estudo e de intervenção no contexto das práticas educativas pode resultar em conflitos ou rivalidades de interpretação sobre o fenômeno educacional. $\mathrm{O}$ autor afirma que "[...] calquier intento de crear un cuerpo de teoría de la educación con independencia de la práctica, que pueda relacionarse más tarde con cierto mundo no teórico de práctica es, en el mejor de los casos, erróneo" (CARR, 2002, p. 66). A partir da provocação desse autor, é possível deduzir a hipótese de que a condição fortemente disciplinar e distante do problema pedagógico que caracteriza a presença dos fundamentos da educação no currículo do curso de Pedagogia repercute em práticas “apostilescas", desarticuladas e, na análise de Carr (2002), rivais ou divergentes.

Uma segunda hipótese, derivada da anterior, apoia-se na impressão de que os fundamentos da educação rompem com a lógica práxica da Pedagogia quando desprezam questões didáticocurriculares associadas aos cotidianos educativos em função da óptica restrita que aplicam às abordagens em educação a partir do foco disciplinar em que se situam ou da crença de que problemas práticos competem às disciplinas de metodologias e organização do trabalho pedagógico, como se teoria e método em Pedagogia pudessem existir de forma desarticulada. As implicações dessa tradição acadêmica de disciplinarização dos fundamentos da educação são agravadas, ainda, no caso das universidades, pela cultura de organização departamental dos Centros e Faculdades e pelo perfil de professores(as) formadores(as), os quais percorrem caminhos de formação stricto sensu por vezes fora do campo da Educação.

Um terceiro eixo de organização curricular que atenda ao pressuposto epistemológico da Pedagogia é a experiência formativa pela imersão nos contextos educativos. $\mathrm{Na}$ perspectiva freiriana, as práticas educativas têm como base ou ponto de partida a realidade vivida como síntese de múltiplas determinações. O reconhecimento dessas múltiplas determinações que instituem o mundo no qual as pessoas experimentam e constroem relações históricas, culturais e políticas, é um pressuposto para a formação social do ser humano como "[...] ser de relações e não só de contatos, que não apenas está no mundo, mas com o mundo. Estar com o mundo resulta de sua abertura à realidade, o que o faz ser o ente de relações que é" (FREIRE, 2009, p. 47). Resulta desse pressuposto ontológico a compreensão de que a experiência formativa no curso de Pedagogia, uma vez voltada ao desenvolvimento de capacidades que fomentem a práxis de profissionais da formação humana, requer ser norteada pela permanente e progressiva imersão e pesquisa em contextos nos quais emergem os desafios, as condições e as possibilidades da intervenção educativa.

A educação como prática social situada em contextos demanda ser compreendida em uma dinâmica complexa de fatores e de processos interligados, cujo movimento pode ser melhor analisado na medida em que se criam e se ativam redes de saberes articulados à atividade concreta dos(as) educadores(as) para conhecer e transformar a realidade que se apresenta multidimensionalmente. As redes que se constituem pela imersão nos contextos dispõem “[...] os

Práxis Educativa, Ponta Grossa, v. 15, e2015528, p. 1-20, 2020

Disponível em: <https://www.revistas2.uepg.br/index.php/praxiseducativa> 
saberes da ciência pedagógica na criação das atividades dos ensinantes e dos aprendentes" (FRANCO; PIMENTA, 2016, p. 550).

$\mathrm{Na}$ relação com os contextos educativos concretos, os(as) estudantes poderão construir compreensões sobre a complexidade de fatores que incidem na produção de sentido e de práticas que põem em ação determinados modos de formação humana dentro e fora das escolas. Trata-se, nessa perspectiva, de lhes oportunizar o desenvolvimento de um olhar contextualizado acerca dos processos conjunturais e cotidianos que constituem o universo das práticas pedagógicas, mais próximo das necessidades educativas capazes de se tornarem objeto de investigação e de intervenção com potencialidade de transformação social por meio da promoção de aprendizagens que visem à emancipação de indivíduos e de grupos.

Pensar a organização de uma dinâmica curricular que se caracterize pelo eixo da imersão em contextos educativos implica a superação de dicotomias que distanciam as instituições de Ensino Superior dos cenários de atividade profissional (NÓVOA, 1998). Tais dicotomias radicam em uma lógica que desconsidera a prática como espaço de produção de saberes e lócus de constituição de capacidades inventivas fundamentais para acessar e pôr em movimento referenciais conceituais muitas vezes apreendidos pelos(as) estudantes sem associação com as dinâmicas do trabalho para o qual se profissionalizam. Uma consequência importante da experiência de imersão é a formulação de parâmetros e tomada de decisões profissionais orientadas pelo reconhecimento das especificidades e das exigências práticas do trabalho, elementos que, quando manejados de maneira mais competente pelo(a) pedagogo(a), lhe possibilitará um melhor protagonismo e autonomia diante das estruturas que o(a) cercam.

Um dispositivo curricular que promove a concretização desse eixo são os Estágios Supervisionados, entendidos como componentes que articulam ao longo do curso de Pedagogia, desde os primeiros períodos, conhecimentos teórico-metodológicos e habilidades operativas pela pesquisa e imersão nos contextos educativos, como já defendido anteriormente. Os estágios aproximam o currículo a realidades que fornecem elementos fundamentais para a identificação do(a) pedagogo(a) com seus âmbitos de atuação, lhe possibilitando a emergência de indagações sobre possibilidades de produção e de mobilização de saberes, tendo a pesquisa do contexto educativo como fio condutor na lógica do conhecer para intervir e transformar. Isso se concretiza quando, a partir de um olhar multidimensional amparado por diferentes saberes e para instrumentalizar sua ação, o(a) estudante é capaz de identificar os problemas situados em contextos, compreender os fenômenos que interferem no processo pedagógico, as condições que caracterizam os sujeitos educativos, pautando aspectos sobre diversidade e diferença, desigualdades sociais, equidade, determinantes ideológicos, etc.

O estágio é, nesse sentido, um movimento de inquietação/mobilização teórica e investigativa (PIMENTA; LIMA, 2017) em cenários concretos de produção de práticas pedagógicas caracterizadas pela reflexividade, contextualização e colaboratividade com as pessoas que participam desse movimento, desde professores(as) formadores(as) aos sujeitos do campo de estágio. Como dispositivo que dinamiza a relação entre teoria e prática, o estágio deve ser um foco de convergência curricular e se espraiar para cenários práticos que contemplem a sala de aula na escola, mas também outros âmbitos profissionais. Igualmente, deve ser orientado por uma política consistente que fomente relações colaborativas entre instituições formadoras e campo de estágio com um claro programa de compromissos mútuos e corresponsabilidades na definição de diretrizes e de formas de acompanhamento do plano de atividades de estudantes, professores(as) formadores(as) e profissionais. Ressalta-se aqui a relevância de articular os fundamentos da educação aos estágios de maneira mais significativa mediante desenhos curriculares que vinculem componentes tradicionalmente teóricos a programas de inserção prática. 
A pedagogia como lócus de formação profissional de educadores(as): desafios epistemológicos e curriculares

As capacidades profissionais construídas em situações formativas caracterizadas pelos eixos apresentados anteriormente perdem potencialidade quando dissociadas de um referencial éticopolítico intrínseco à defesa da educação como direito humano e social e da escola pública como lócus de formação para a democracia. Desse modo, o quarto eixo proposto diz respeito ao compromisso com a finalidade democrática dos processos educativos e com a escola pública.

$\mathrm{Na}$ óptica do compromisso com a democracia, a educação é concebida como prática social crítica e transformadora. Diante do quadro problemático que se expõe com o avanço da ação mercadológica no campo das políticas educacionais e, mais especificamente, na rentabilização da formação docente por conglomerados financeiros próprios das ideologias neoliberais que operam nas estruturas do Estado, é preciso assumir a necessidade de situar propostas de organização curricular do curso de Pedagogia nessa concepção. Formar profissionais no curso de Pedagogia.

Em um país de desigualdades genealógicas com desdobramentos que se acentuam em uma época de retrocessos, a formação no curso de Pedagogia requer ser alinhada a uma lógica multidimensional de ensino "[...] que o compreenda como uma práxis educativa pedagógica, que considere as contradições e dilemas dos contextos nos quais se realiza” (PIMENTA, 2019, p. 35). É nos territórios da escola pública brasileira que essa lógica poderá impactar práticas docentes que superem a situação de não aprendizagem dos estudantes para além de uma resolução que depende de prescrições metodológicas, como sugerem os paradigmas produtivistas embutidos em discursos de competências e boas práticas, como na recém publicada Base Nacional de Formação de Professores(as) para a Educação Básica (BRASIL, 2019).

A fim de que o trabalho educativo se organize na direção contrária da lógica presente no documento citado anteriormente, torna-se necessário vinculá-lo a um referencial que lhe confira identidade como ato formativo intencional enraizado na reflexão sobre o sentido e os modos de ação, visando à aprendizagem pela apropriação e pela ressignificação de conhecimentos, de atitudes e de procedimentos. Esse referencial está sustentado na Didática Crítica. Assume-se, portanto, como um último eixo estruturante do curso de Pedagogia, aqui proposto, o estudo da Didática em suas conexões com as bases teórico-práticas relação pedagógica e as especificidades dos objetos do ensino.

A Didática é uma chave conceitual e metodológica fundamental na abertura das possibilidades de análise e de intervenção do "quê-fazer" estruturante do trabalho pedagógico, concebendo a mediação educativa como "[...] una actividad histórica y social en constante construcción, que tiene lugar en un determinado contexto económico, social, cultural e politico [...]" (ÁLVAREZ MENDEZ, 2001, p. 122). Com efeito, o campo da Didática é mais amplo do que os esquemas de organização de uma disciplina sobre Didática nos currículos, mas entende-se como de fundamental importância a existência de um componente de Didática Geral, o que exprime uma preocupação com a contextualização mais ampla do fenômeno pedagógico e, conectado a ele, o fenômeno do ensino. O enfoque da Didática Geral figura como elemento estruturante que permite que o fenômeno do ensino seja compreendido em um contexto de complexas relações sistêmicas envolvendo o saber disciplinar, mas que, além dessa referência, se orientam pela crítica pedagógica mais ampla da qual emergem as finalidades e os princípios que dão identidade ao trabalho educativo dentro de um projeto de sociedade e de formação humana.

Efetivamente, a base epistemológica dos objetos de ensino é um aspecto fundamental na composição das estratégias didáticas, uma vez que os processos de aprendizagem ocorrem diferenciadamente em função da natureza disciplinar e do processo metodológico de construção do conhecimento tanto para quem ensina quanto para quem aprende. Nesse sentido, não é salutar a contraposição entre a "Didática geral da relação pedagógica" e as "didáticas disciplinares do ensino de conteúdos específicos". Se a forte presença de componentes curriculares voltados à abordagem metodológica de conteúdos específicos pode fortalecer, por um lado, a aprendizagem

Práxis Educativa, Ponta Grossa, v. 15, e2015528, p. 1-20, 2020

Disponível em: < https://www.revistas2.uepg.br/index.php/praxiseducativa> 
docente de estratégias de ensino fundamentadas pelas pesquisas didáticas nos campos disciplinares do currículo; por outro lado, pode fragilizar a Didática Geral como elemento estruturante da formação de pedagogos(as), incitando um definhamento desse campo. Isso resultaria na minimização da importância da formação pedagógica mais ampla para além da que se atrela ao ensino de conteúdos específicos e que os situa no debate sobre a Pedagogia e a formação humana. Sob essa ênfase, o caráter pedagógico do ensino pode ser reduzido a uma dimensão instrucional representada em métodos de transposição didática de conteúdos disciplinares.

À medida que os cursos de Pedagogia se afastam de um referencial amplo e crítico sobre a Didática, abre-se espaço para que propostas desintelectualizantes e instrumentalizantes do trabalho docente se consolidem, limitando a formação de professores(as) como intelectuais críticos(as) e profissionais do desenvolvimento humano à preparação para a transposição técnica de conteúdos disciplinares. Soluções dessa natureza configuram respostas neotecnicistas alinhadas às exigências do modo de produção capitalista, deslocando o sentido social da escola como espaço de construção da democratização do saber e formação cidadã para o sentido da escola como, tão somente, espaço de aquisição de competências necessárias à vida produtiva e ao disciplinamento social.

\section{Considerações finais}

Concluída a apresentação dos eixos estruturantes propostos para a organização de cursos consoantes com o entendimento da Pedagogia como um campo de conhecimento, cabe, como consideração final, argumentarmos que uma proposta de curso que vá ao encontro do que foi aqui defendido não é possível sob a lógica da mercantilização da educação, que tem imperado em nosso país nas últimas décadas. Duas pesquisas produzidas sobre os cursos de Pedagogia oferecidos no estado de São Paulo (PIMENTA et al., 2017; PEDROSO et al., 2019) evidenciam, por um lado, que esses cursos, quando oferecidos por Instituições de Ensino Superior (IES) privadas, com raríssimas exceções, não oferecem as condições mínimas para que seus projetos pedagógicos possam inovar, uma vez que, ao operarem sob a lógica da maximização dos lucros, oferecem péssimas condições para o trabalho dos(as) professores(as) formadores(as), assim como para as aprendizagens dos(as) futuros(as) pedagogos(as). Por outro lado, na maior parte das IES públicas pesquisadas, muitas das ideias aqui expostas já estão materializadas em seus projetos pedagógicos. Mesmo assim, as IES públicas estão funcionando com restrições orçamentárias cada vez maiores, em especial nos quatro últimos anos, o que também dificulta a operacionalização de projetos pedagógicos inovadores. Essa situação é ainda exponencialmente agravada no contexto da pandemia do coronavírus, que já prenuncia um aprofundamento ainda maior nos cortes de verbas para a área de educação.

Finalmente, é importante registrar o nosso entendimento de que esse contexto da pandemia - no qual foi produzido o presente artigo - clama por vários outros estudos e denúncias mais urgentes no campo educacional, mas que não podem calar nossa utopia de defender a educação pública de qualidade socialmente referenciada e a Pedagogia como uma ciência implicada em diferentes processos educativos que, pela práxis profissional de pedagogos(as), colaboram ativamente na transformação da sociedade.

Contemplar tais processos na formulação e no desenvolvimento curricular da formação inicial de pedagogos(as) exige uma ruptura de compreensão do que constitui a Pedagogia como campo de conhecimentos, deslocando-a do sentido de tecnologia da ação docente para o sentido de Ciência da Educação. Sob a compreensão da Pedagogia como Ciência da Educação, é possível ampliar as possibilidades de crítica e de criação curricular orientadas para o fortalecimento da capacidade formativa do curso em sua complexidade de funções que se traduzem em um perfil profissional de pedagogos(as) comprometidos(as) com a finalidade humanizatória da educação e o seu caráter público.

Práxis Educativa, Ponta Grossa, v. 15, e2015528, p. 1-20, 2020

Disponível em: <https://www.revistas2.uepg.br/index.php/praxiseducativa> 
A pedagogia como lócus de formação profissional de educadores(as): desafios epistemológicos e curriculares

\section{Referências}

AFONSO, A. J. A propósito das Ciências da Educação: algumas reflexões. In: CONSELHO NACIONAL DE EDUCAÇÃO. O Estado da Educação e as Ciências da Educação: leituras críticas e desafios. Lisboa, Portugal: CNE, 2013. p. 13-19.

ALVAREZ MÉNDEZ, J. M. Entender la didáctica, entender el curriculum. Madrid: Miño y Dávila, 2001.

BOAVIDA, J.; AMADO, J. Ciências da Educação: epistemologia, identidade e perspectivas. Coimbra: Imprensa da Universidade de Coimbra, 2008.

BRASIL. Lei N N $^{\text {4.024, de }} 20$ de dezembro de 1961. Fixa as Diretrizes e Bases da Educação Nacional. Diário Oficial da União: seção 1, Brasília, DF, p. 11.429, 27 dez. 1961.

BRASIL. Resolução No 1, de 15 de maio de 2006. Institui Diretrizes Curriculares Nacionais para o Curso de Graduação em Pedagogia, licenciatura. Diário Oficial da União: seção 1, Brasília, DF, n. 92, p. 11-12, 16 maio 2006.

BRASIL. Resolução $\mathbf{N}^{\mathbf{0}}$ 2, de 20 de dezembro de 2019. Define as Diretrizes Curriculares Nacionais para a Formação Inicial de Professores para a Educação Básica e institui a Base Nacional Comum para a Formação Inicial de Professores da Educação Básica (BNC-Formação). Brasília: Ministério da Educação, Conselho Nacional de Educação, Conselho Pleno, [2019]. Disponível em: <http://portal.mec.gov.br/docman/dezembro-2019-pdf/135951-rcp002-19/file>. Acesso em: 1 jun. 2020.

CARR, W. Una teoría para la educación: hacia una investigación educativa crítica. 3. ed. Madrid: Ediciones Morata, 2002.

CARvalho, A. D. A epistemologia da Ciências da Educação. Porto: Afrontamento, 1996.

FRANCO, M. A. S. Pedagogia como ciência da educação. 2. ed. São Paulo: Cortez, 2008.

FRANCO, M. A. S.; PIMENTA, S. G. Didática multidimensional: por uma sistematização conceitual. Educação \& Sociedade, Campinas, v. 37, n. 135, p. 539-553, maio/jun. 2016. DOI: https://doi.org/10.1590/ES0101-73302016136048

FRANCO, M. A. S.; LIBÂNEO, J. C.; PIMENTA, S. G. As dimensões constitutivas da Pedagogia como campo de conhecimento. Revista Educação em foco, Belo Horizonte, v. 14, n. 17, p. 5578, 2011. DOI: http://dx.doi.org/10.24934/eef.v14i17.103

FRANCO, M. A.; LIBÂNEO, J. C.; PIMENTA, S. G. Elementos para a formulação de Diretrizes Curriculares para cursos de Pedagogia. Cadernos de Pesquisa, São Paulo, v. 37, n. 130, p. 63-97, jan./abr. 2007. DOI: http://dx.doi.org/10.1590/S0100-15742007000100005

FREIRE, P. Educação como prática da liberdade. Rio de Janeiro: Paz e Terra, 2009.

FREIRE, P. Papel da educação na humanização. Revista da FAEEBA, Salvador, v. 6, n. 7, p. 17, jan./jun. 1997.

HOUSSAYE, J. Pedagogia: justiça para uma causa perdida?. In: HOUSSAYE, J. et al. (Orgs.). Manifesto a favor dos pedagogos. Porto Alegre: Artmed, 2004. p. 9-45.

LIBÂNEO, J. C. Pedagogia e pedagogos, para quê? 12. ed. São Paulo: Cortez, 2010. 
MARX, K.; ENGELS, F. A ideologia alemã. São Paulo: Livraria Editora Ciências Humanas Ltda., 1979.

NÓVOA, A. O passado e o presente dos professores. In: NÓVOA, A. (Org.) Profissão professor. Porto: Porto Editora, 1998. p. 12-45.

PEDROSO, C. C. A. et al. Cursos de Pedagogia: inovações na formação de professores polivalentes. São Paulo: Cortez, 2019.

PEDROSO, C. C. A.; PINTO, U. A. Ações integradoras e de pesquisa na formação inicial do professor polivalente: experiências inovadoras em cursos de Pedagogia no Estado de São Paulo. In: PEDROSO, C. C. A. et al. (Orgs.). Cursos de Pedagogia: inovações na formação de professores polivalentes. 1. ed. São Paulo: Cortez, 2019. p. 155-196.

PIMENTA, S. G. As ondas críticas da didática em movimento: resistência ao tecnicismo/neotecnicismo neoliberal. In: SILVA, M.; NASCIMENTO, O. C.; ZEN, G. C. (Orgs.). Didática: abordagens teóricas contemporâneas. Salvador: EDUFBA, 2019. p. 19-64.

PIMENTA, S. G. Pedagogia, ciência da educação?. São Paulo: Cortez, 1996.

PIMENTA, S. G. O estágio na formação de professores: unidade entre teoria e prática? Cadernos de Pesquisa, São Paulo, n. 94, p. 58-73, ago. 1995.

PIMENTA, S. G. Para uma re-significação da didática - ciências da educação, pedagogia e didática (uma revisão conceitual e uma síntese provisória). In: PIMENTA, S. G. (Org.). Didática e formação de professores: percursos e perspectivas no Brasil e em Portugal. 3. ed. São Paulo: Cortez, 2010. p. 23-87.

PIMENTA, S. G. et al. A. Os cursos de licenciatura em Pedagogia: fragilidades na formação inicial do professor polivalente. Educação e Pesquisa, São Paulo, v. 43, n. 1, p. 15-30, jan./mar. 2017. DOI: https://doi.org/10.1590/s1517-9702201701152815

PIMENTA, S. G.; LIMA, M. S. L Estágio e docência. 8. ed. ver. atual. e ampl. São Paulo: Cortez, 2017.

PINTO, U. A. Graduação em Pedagogia: apontamentos para um curso de bacharelado. In: SILVESTRE, M. A.; PINTO, U. A. (Orgs.). Curso de Pedagogia: avanços e limites após as Diretrizes Curriculares Nacionais. São Paulo: Cortez, 2018. p. 163-184.

PINTO, U. A. Pedagogia escolar: coordenação pedagógica e gestão educacional. São Paulo: Cortez Editora, 2011.

SAVIANI, D. História das ideias pedagógicas no Brasil. 3. ed. rev. 1. reimpr. Campinas: Editora Autores Associados, 2011.

SAVIANI, D. Educação socialista, pedagogia histórico-crítica e os desafios da sociedade de classes. In: LOMBARDI, J. C.; SAVIANI, D. (Orgs.). Marxismo e Educação: debates contemporâneos. 2. ed. Campinas: Autores Associados, 2008. p. 223-274.

SAVIANI, D. Pedagogia: o espaço da educação na universidade. Cadernos de Pesquisa, São Paulo, v. 37, n. 130, p. 99-134, jan./abr. 2007. DOI: https://doi.org/10.1590/S010015742007000100006 
SCHMIED-KOWARZIK, W. Pedagogia dialética: de Aristóteles a Paulo Freire. São Paulo: Brasiliense, 1988.

SEVERINO, A. J. A Pesquisa em Educação: a abordagem crítico-dialética e suas implicações na formação do educador. Contrapontos, Itajaí, v. 1, n. 1, p. 11-22, jan./jun. 2001.

SEVERO, J. L. R. L. A formação inicial de pedagogos para a Educação em contextos não escolares: apontamentos críticos e alternativas curriculares. In: SILVESTRE, M. A.; PINTO, U. A. (Orgs.). Curso de Pedagogia: avanços e limites após as Diretrizes Curriculares Nacionais. São Paulo: Cortez, 2018. p. 127-162.

SILVA JUNIOR, C. A. Prefácio. In: PEDROSO, C. C. A. et al. Cursos de Pedagogia: inovações na formação de professores polivalentes. 1. ed. São Paulo: Cortez, 2019. p. 5-15.

TOURIÑAN LÓPEZ, J. M. Imagen social de la Pedagogía. La Pedagogía del futuro y el futuro de la Pedagogía. In: COLOM CAÑELLAS, A. J. et al. La Pedagogía hoy. Santiago de Compostela: Andavira Ediciones, 2018. p. 115-135.

VÁZQUEZ, A. S. Filosofia da práxis. Rio de Janeiro: Paz e Terra, 1968.

WACHOWICZ, L. A. Pedagogia mediadora. Petrópolis: Vozes, 2009.

ZULUAGA GARCÉS, O. L. Pasado y presente de la Pedagogía y la Didáctica. In: ZAPATA, V. et al. (Orgs.). Objeto y método de la Pedagogía. Medellín: Universidad de Antioquia, 1993. p. $119-125$.

Recebido em 25/05/2020

Aceito em 02/06/2020

Publicado online em 06/06/2020 